\title{
ИНСТИТУЦИОНАЛЬНЫЕ ОСНОВЫ РОССИЙСКОЙ ФЕДЕРАЦИИ В СФЕРЕ МЕЖДУНАРОДНОГО ИНВЕСТИЦИОННОГО СОТРУДНИЧЕСТВА
}

\begin{abstract}
Аннотация: Привлечение крупномасштабных иностранных инвестиций в экономику страны является однойиз важнейиих задач государства. Динамичность и эффективность развития экономики любого государства во многом зависят от величины иностранных инвестиций.В статье автор проводит анализ институтов Российской Федерации, ответственньх за привлечение иностранных инвестиций и улучшение инвестищионного климата. Подробно рассматриваются полномочия и обязанности Правительства РФ в сфере международного инвестиционного сотрудничества. Даётся описание факторов, от которых зависит решение потенциильного инвестора об объекте капиталовложений, которое является результатом его оценки соотношения риска вложения и отдачи инвестиций. В статье рассказывается о Консультативном совете по иностранным инвестициям в России (далее-КСИИ) - органе, созданном в целях обеспечения проведения последовательнойи скоординированнойгосударственнойполитики по привлечению иностранных инвестииий в экономику Российской Федераџии, а именно об организаџионной структуре КСИИ, о прочедуре обновления состава КСИИ, о современном составе КСИИ, описывается процедура формирования рабочих групп КСИИ.Анализ институциональной основы Российской Федерации в сферемеждународного инвестиционного сотрудничества свидетельствует об активномучастиигосударственных органов в этом направлении. В целом можно констатировать, что в России сохраняется благоприятная экономическая ситуация для долгосрочных инвестиџий и принимаются меры по стимулированию инвестиционных процессов.

Review: Attracting large-scale foreign investments into its economy is one of the key goals of any state. Dynamic an efficient development of economy of any state much depend on an amount of foreign investments. In this article the author analyzes the institutions of the Russian Federation responsible for attracting foreign investments and improvement of the investment climate. The article contains detailed analysis of the competence and obligations of the Government of the Russian Federation in the sphere of international investment cooperation. The author describes the factors, on which a decision of a potential investor on an amount of investment depends, resulting in his evaluation of the correlation of the risks of investment and profits. The article also provides information on the Foreign Investment Advisory Council (FIAC), which is the body formed in order to guarantee and implement consecutive and coordinated state policy in the sphere of attracting foreign investments into the economy of the Russian Federation. The article includes information on its structure, renewal of the Council, its current composition, procedure for the formation of the working groups. Analysis of the institutional basis of the Russian Federation in the sphere of investment cooperation shows active participation of the state bodies in this sphere. Generally, one may state that the economic situation in Russia is currently beneficial for the long-term investments, and the measures are taken in order to stimulate investment processes. Ключевые слова: Инвестиции, Правительство, экономика, международныій, инвестиционный, КСИИ, Россия, иностранный, сотрудничество, инвестор
\end{abstract}

Keywords: investments, Government, economy, international, investment, FIAC, Russia, foreign, cooperation, investor.

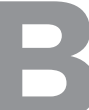

сфере регулирования инвестиционных отношений в Российской Федерации по контролю за исполнением норм международных договоров и национального законодательства значительными полномочиями наделено Правительство РФ и подчинённые ему органы исполнительной ветви власти. Так, в частности, нормы права Федерального закона от 09.07.1999 г. «Об иностранных инвестициях в Российской Федерации» обязывают Правительство РФ:
- разработать и одобрить правила аккредитации филиалов иностранных юридических лиц в РФ;

- одобрить перечень приоритетных норм инвестиционных проектов и процедуру их регистрации;

- определять критерии неблагоприятных изменений в законодательном регулировании инвестиций в целях применения «дедушкиной оговорки»;

- определять критерии целесообразности введения запретов и ограничений на осуществление иностранных инвестиций. 
DOI: $10.7256 / 1811-9018.2013 .10 .8919$

При цитировании этой статьи сноска на dоі обязательна

\section{Право и политика $10(166) \cdot 2013$}

В соответствии с указанным законом, Правительство РФ уполномочено:

- осуществлять контроль за подготовкой и подписанием инвестиционных соглашений о реализации крупномасштабных инвестиционных проектов;

- контролировать исполнение иностранным инвестором и российскими коммерческими организациями с иностранными инвестициями обязательств по инвестиционным отношениям;

- лишать иностранного инвестора и российскую организацию с иностранными инвестициями льгот в случае нарушения ими законодательства РФ.

Вышеперечисленные полномочия предопределяют роль Правительства РФ и его нормативно-правовых актов в регулировании правоотношений с иностранным инвестором. ${ }^{1}$ Следует отметить, что в соответствии с законодательством Правительство РФ разрабатывает и реализует государственную политику в сфере международного инвестиционного сотрудничества. ${ }^{2}$ Такие полномочия, предоставленные законодателем Правительству РФ вполне объяснимы, поскольку привлечение крупномасштабных иностранных инвестиций в экономику страны является одной из важнейших задач государства. ${ }^{3}$ Оно рассматривается в качестве одного из средств выхода страны из экономического кризиса. Именно инвестиции западных стран обеспечили быстрый экономический подъём Китая, развивающихся стран Латинской Америки, Юго-Восточной Азии и Африки. ${ }^{4}$

Динамичность и эффективность развития экономики любого государства во многом зависят от величины иностранных инвестиций, направленных на расшире-

\footnotetext{
${ }^{1}$ См. напр.: Распоряжение Правительства РФ от 05.07.2001 г. № 911-р. «О передаче прав и обязанностей по Соглашению о разделе продукции по нефтегазоконденсатным месторождениям Чайво, Одопту-Аркутун-Дагинское (проект «Сахалин-1») иностранному инвестору». СЗ РФ. 2001. № 29. Ст. 3040; Распоряжение Правительства РФ от 09.17.2000 г. № 1411-р. «О деятельности федеральных органов исполнительной власти по обеспечению и рассмотрению вопросов, связанных с иностранными инвестициями». СЗ РФ. 2000. № 42. Ст. 4159.

${ }^{2}$ См. напр.: Федеральный конституционный закон от 17.12.1997 г. № 2-ФКЗ «О Правительстве Российской Федерации». СЗ РФ. 1997. № 51. Ст. 5712; Федеральный закон от 09.07.1999. № 160-Ф3 (ред. от 03.06.2006) «Об иностранных инвестициях в Российской Федерации» СЗ РФ. 1999. № 28. Ст. 3493.

${ }^{3}$ Фархутдинов И.З. Условия доступа иностранного инвестора на рынки России и этапы его хозяйственной деятельности. // Право и политика. 2008. № 9. - С. 21-42.

4 Лисица В.Н. Международные инвестиционные соглашения (договоры, контракты). Автореф. дис. ... канд. юрид. наук - Новосибирск.: ИФиП, Сибирского отделения РАН, 2003. - С. 3.
}

ние существующих производственных мощностей, их реконструкцию, на современном научно-техническом уровне, создания производств, выпускающих продукцию с новыми потребительскими свойствами. ${ }^{5}$

Для реализации этой задачи требуется увеличение притока инвестиций в национальную экономику, который зависит от инвестиционного климата в государстве-импортёре капитала.

Иностранный инвестор обладает широким выбором государств с благоприятными условиями для капиталовложений. Решение потенциального инвестора об объекте капиталовложений является результатом его оценки соотношения риска вложения и отдачи инвестиций. Оно зависит от следующих групп факторов:

- стабильности состояния национальной экономики принимающего инвестиции государства (колебание курса национальной валюты, рост валового национального продукта, постоянный рост (даже незначительный) производства, правовой режим в сфере предпринимательства, уровень налогообложения и др.);

- эффективности той или иной отрасли национальности принимающего государства, в которую осуществляются инвестиции, её места в экономической системе, конкурентоспособности и т.д.;

- эффективности самого предприятия, которое становится объектом для инвестирования, особенностей его внутренней организации, специфики поведения на рынке. ${ }^{6}$

Согласно ст. 24 Ф3 «Об иностранных инвестициях в Российской Федерации» от 09.07.1999 г., Правительство РФ определяет федеральный орган исполнительной власти, ответственный за координацию привлечения ПИИ в экономику Российской Федерации. В соответствии с Постановлением Правительства РФ от 21.12.1999 г. № $1419^{7}$ таким органом является Министерство экономики РФ (в настоящее время - Министерство экономического развития).

\footnotetext{
${ }_{5}^{5}$ Евтеева М.С. Международные двусторонние инвестиционные соглашения. - М., 2002. - С. 9.

${ }^{6}$ Асланов А. Р. Международные соглашения как источник правового регулирования международной инвестиционной деятельности. Интернет-версия журнала Право: теория и практика. 2003. № 9. (режим доступа: http://www.yurclub.ru/).

${ }^{7}$ Постановление Правительства РФ от 21.12.1999 г. № 1419 «О федеральном органе исполнительной власти, ответственном за координацию деятельности федеральных органов исполнительной власти по привлечению в экономику Российской Федерации прямых иностранных инвестиций и аккредитацию филиалов иностранных юридических лиц». СЗ РФ. 1999. № 52. Ст. 6412.
} 
Постановлением Правительства РФ от 18.09.2004 г. № 487, ${ }^{8}$ для обеспечения проведения последовательной и скоординированной государственной политики в области активизации работы по привлечению иностранных инвестиций в экономику Российской Федерации был образован Консультативный совет по иностранным инвестициям в России (далее - КСИИ).

Председателем Консультативного совета является Председатель Правительства РФ, а его заместителем Министр экономического развития РФ.

В организационной структуре КСИИ действуют Постоянный комитет КСИИ и девять рабочих групп.

Постоянный комитет КСИИ был создан в соответствии с распоряжением Правительства Российской Федерации в июне 1995 г. Его основной функцией является координация деятельности федеральных органов исполнительной ветви власти по реализации рекомендаций и предложений КСИИ, обеспечение работы КСИИ в период между ежегодными заседаниями, а также разработка предложений для рассмотрения в Правительстве Российской Федерации.

Председателем Постоянного комитета КСИИ является Министр экономического развития РФ, а заместителем председателя КСИИ - Министр финансов РФ.

Секретариат Постоянного комитета КСИИ функционирует в рамках Министерства экономического развития и возглавляется ответственным секретарём, которым является директор Департамента инвестиционной политики указанного министерства.

В состав Постоянного комитета, который утверждается его председателем, входят представители (в основном руководство) ряда федеральных органов исполнительной ветви власти, Аппарата Правительства Российской Федерации, Центрального банка России, а также представители в России иностранных компаний-членов КСИИ и представители ассоциированных членов Совета - Ассоциации Европейского бизнеса в России, Российско-Германской Внешнеторговой палаты и Американской торговой палаты в России.

Обеспечение деятельности КСИИ и координация взаимодействия рабочих групп в его составе возложены на Министерство экономического развития Российской Федерации.

\footnotetext{
${ }^{8}$ Постановление Правительства РФ от 18.09.2004 г. № 487 «О Консультативном совете по иностранным инвестициям в России». С3 РФ. 2004. № 39. 3866.
}

Пленарные заседания КСИИ проводятся под руководством Председателя Правительства РФ при участии глав зарубежных компаний-членов КСИИ один раз в год в третий понедельник октября. С момента образования Совета прошло 22 заседания (последнее состоялось 20.10.2008 г.).

Подготовку материалов и проведение заседаний осуществляет Министерство экономического развития. Рекомендации и предложения иностранных компанийчленов КСИИ, по различным проблемам, влияющим на инвестиционный климат в России, рассматриваются заинтересованными федеральными органами исполнительной ветви власти и обсуждаются совместно с членами КСИИ на заседаниях Совета.

Доклад об итогах рассмотрения этих рекомендаций, подготовленный Министерством экономического развития, направляется в Правительство РФ для принятия соответствующих мер в сфере инвестиционной деятельности, а также - для использования при подготовке очередного заседания КСИИ.

Для повышения эффективной работы Совета, постоянно проводится обновление его состава. В соответствии с утверждённым в июле 2005 г. Положением «О ротации компаний (организаций)-членов Консультативного совета по иностранным инвестициям в России» определены принципы формирования его состава, порядок приёма новых членов и вывода из состава КСИИ, а также - правовой статус наблюдателя КСИИ. Последняя ротация проводилась в июле 2007 г. В состав совета принимаются компании, сфера деятельности которых соответствует приоритетным направлениям привлечения инвестиций в экономику нашего государства, способствует созданию положительного имиджа России как страны, принимающей инвестиции, а также представляющие: а) государства, являющиеся ключевыми инвесторами в российскую экономику; б) различные секторы экономики; в) крупный и средний бизнес. В настоящее время в состав КСИИ входят 33 иностранные компании и организации, из которых 27 являются членами КСИИ: БиЭйчПиБиллитон Австралия; БАТ, Эрнст энд Янг - Великобритания; САН Групп - Индия; Теленор - Норвегия; Каргилл, Кока-Кола, Марс, ПепсиКо, Проктер энд Гэмбл, Форд Мотор Компани, ЭксонМобил, Юнайтед Текнолоджис - США; Рено, Шлюберже - Франция; БАСФ, МЕТРО Групп, Сименс, Дойче Банк - ФРГ; Нестле - Швейцария; Тетра Лаваль - Швеция; Мицубиси Корпорейшн Япония, а также БП - Великобритания/США; Ройял/ 
DOI: $10.7256 / 1811-9018.2013 .10 .8919$

При цитировании этой статьи сноска на доі обязательна

\section{Право и политика 10 (166) • 2013}

Датч Шелл-Великобритания/Нидерланды; Юнилевер

- Великобритания/Нидерланды; Всемирный Банк; Европейский Банк Реконструкции и Развития и 6 компаний - со статусом наблюдателей: Англо Американ - Великобритания/ЮАР; Алкоа, Крафт Фудс - США; Тоталь - Франция; ИточуКорпорейшн и Мицубиси энд Ко - Япония.

Заявки от компаний, желающих войти в состав КСИИ рассматриваются на заседаниях действующей группы по ротации. Окончательное решение об исключении и приёме новых членов Совета принимает Председатель Постоянного комитета КСИИ-Министр экономического развития. Это решение в письменной форме доводится до компаний ответственным секретарём Постоянного комитета КСИИ.

Рабочие группы КСИИ, как его структурные подразделения, играют важную роль. На их заседаниях, с участием представителей федеральных органов исполнительной ветви власти и иностранных компанийчленов КСИИ, рассматриваются вопросы улучшения экономических условий для деятельности в России иностранных инвесторов, устранения административных барьеров, создания эффективной системы гарантирования прав инвесторов, совершенствования налогового и таможенного законодательства, законодательства в области природопользования и инновационной деятельности, получения доступа к высоким технологиям.

В настоящее время в структуре КСИИ функционируют девять рабочих групп, руководители которых (с российской стороны) утверждены Председателем КСИИ.

Как правило, группы создаются по инициативе иностранных инвесторов в случаях возникновения их интереса по вопросам инвестиционной деятельности. Существуют два варианта создания таких групп:

1. Координатор членов КСИИ вместе с компаниями встречаются с представителем соответствующего министерства и обсуждают вопрос о создании группы, определяют перечень проблем, которые они предполагают обсудить в рамках новой рабочей группы КСИИ, после чего вопрос включается в повестку заседания Постоянного комитета КСИИ.

2. Компании подают заявление об участии в работе заседания Постоянного комитета КСИИ, на котором рассматривается их предложение о создании новой группы и принимается решение о поручении соответствующему министерству окончательно проработать этот вопрос совместно с членами КСИИ.
В случае положительного решения о создании новой группы, руководство которой поручается подведомственному министру, определяется круг обсуждаемых проблем. После этого, необходимые документы направляются главе Министерства экономического развития, который обращается к Председателю КСИИ с предложением утвердить новую группу.

Инициатором предложения о создании новой рабочей группы на заседании Постоянного Комитета КСИИ может выступить любое профильное министерство. В этих целях необходимо найти заинтересованные компании-члены КСИИ и определить круг обсуждаемых проблем.

Таким образом, анализ институциональной основы Российской Федерации в сфере международного инвестиционного сотрудничества свидетельствует об активном участии государственных органов в этом направлении.

В целом, можно констатировать, что в России сохраняется благоприятная экономическая ситуация для долгосрочных инвестиций и принимаются меры по стимулированию инвестиционных процессов.

Члены Консультативного совета осуществили ряд мер по улучшению инвестиционного имиджа России за рубежом. Был составлен доклад об инвестиционной привлекательности России, на основе глав 51-й международной корпорации. Обеспечено участие первых лиц компаний-членов Консультативного совета по иностранным инвестициям в России на XII Петербургском международном экономическом форуме и проведена кампания по объективному освещению состояния российской экономики в зарубежных средствах массовой информации. Особое внимание было уделено подготовке приложений к газетам «Вашингтон пост» («Washington Post») и «Дейли Телеграф» («Daily Telegraph») - «Российская реальность: подробности» («Russia Beyond The Headlines»), в которых представлены комментарии первых лиц компаний-членов Консультативного совета о состоянии российской экономики и позитивном имидже нашего государства.

В рамках XII Петербургского международного экономического форума был проведён круглый стол на тему «Корпоративное управление в России глазами иностранных инвесторов», на котором состоялась презентация опроса руководителей компаний, отразившего положительную динамику в развитии инвестиционного климата в России. 
DOI: 10.7256/1811-9018.2013.10.8919

При цитировании этой статьи сноска на dоі обязательна

Государственные институты и правовые системы

При содействии членов Консультативного совета на международном инвестиционном форуме «Сочи-2008» было организовано проведение круглого стола «Бренд Россия», призванного содействовать формированию положительного инвестиционного имиджа России для потенциальных инвесторов.

В целях дальнейшего улучшения условий предпринимательской деятельности участники заседания Консультативного совета по иностранным инвестициям в России сосредотачивают свои усилия на решении актуальных задач, среди которых приоритетным остаётся улучшение инвестиционного климата. Под их руководством были подготовлены и проведены:

- запуск информационного портала «Invest in Russia» с целью доведения объективной информации до целевой аудитории - представителей государственной власти различных стран мира, руководителей международных организаций, институтов и транснациональных корпораций;

- ключевые российские форумы, а также инвестиционные и экономические мероприятия международного уровня;

- формирование пула редакторов и руководителей ведущих международных медиаизданий и холдингов, с целью объективного восприятия России на международной арене;

- социологические исследования мнений руководителей иностранных компаний.

Проводимый на государственном и международном уровнях комплекс правовых, административно-организационных, политических и социально-экономических мер приводит автора к выводу о том, что Россия становится равноправным участником международного рынка труда, гарантируя соблюдение основных прав и свобод для иностранных инвесторов.

\section{Библиография:}

1. Асланов А. Р. Международные соглашения как источник правового регулирования международной инвестиционной деятельности. Интернет-версия журнала Право: теория и практика. 2003, № 9 (режим доступа: http://www.yurclub.ru/).

2. Евтеева М.С. Международные двусторонние инвестиционные соглашения. - М., 2002. - С. 9.

3. Лисица В.Н. Международные инвестиционные соглашения (договоры, контракты). Автореф. дис. ... канд. юрид. наук-Новосибирск.: ИФиП, Сибирского отделения РАН, 2003. - С. 3.

4. Фархутдинов И.З. Условия доступа иностранного инвестора на рынки России и этапы его хозяйственной деятельности. // Право и политика. 2008. № 9. - С. 21-42.

\section{References (transliteration):}

1. Aslanov A. R. Mezhdunarodnye soglasheniya kak istochnik pravovogo regulirovaniya mezhdunarodnoi investitsionnoi deyatel'nosti. Internet-versiya zhurnala Pravo: teoriya i praktika. 2003, № 9 (rezhim dostupa: http://www.yurclub.ru/).

2. Evteeva M.S. Mezhdunarodnye dvustoronnie investitsionnye soglasheniya. - M., 2002. - S. 9.

3. Lisitsa V.N. Mezhdunarodnye investitsionnye soglasheniya (dogovory, kontrakty). Avtoref. dis. ... kand. yurid. nauk-Novosibirsk.: IFiP, Cibirskogo otdeleniya RAN, 2003. - S. 3.

4. Farkhutdinov I.Z. Usloviya dostupa inostrannogo investora na rynki Rossii i etapy ego khozyaistvennoi deyatel'nosti. // Pravo i politika. 2008. № 9. - S. 21-42. 